\title{
Detailed 3D Fault Representations for the 2019 Ridgecrest, California, Earthquake Sequence
}

\author{
Andreas Plesch ${ }^{* 1}$, John H. Shaw', Zachary E. Ross², and Egill Hauksson ${ }^{2}$
}

\begin{abstract}
We present new 3D source fault representations for the 2019 M 6.4 and M 7.1 Ridgecrest earthquake sequence. These representations are based on relocated hypocenter catalogs expanded by template matching and focal mechanisms for M 4 and larger events. Following the approach of Riesner et al. (2017), we generate reproducible 3D fault geometries by integrating hypocenter, nodal plane, and surface rupture trace constraints. We used the southwest-northeast-striking nodal plane of the 4 July $2019 \mathrm{M} 6.4$ event to constrain the initial representation of the southern Little Lake fault (SLLF), both in terms of location and orientation. The eastern Little Lake fault (ELLF) was constrained by the 5 July 2019 M 7.1 hypocenter and nodal planes of M 4 and larger aftershocks aligned with the main trend of the fault. The approach follows a defined workflow that assigns weights to a variety of geometric constraints. These main constraints have a high weight relative to that of individual hypocenters, ensuring that small aftershocks are applied as weaker constraints. The resulting fault planes can be considered averages of the hypocentral locations respecting nodal plane orientations. For the final representation we added detailed, fieldmapped rupture traces as strong constraints. The resulting fault representations are generally smooth but nonplanar and dip steeply. The SLLF and ELLF intersect at nearly right angles and cross on another. The ELLF representation is truncated at the Airport Lake fault to the north and the Garlock fault to the south, consistent with the aftershock pattern. The terminations of the SLLF representation are controlled by aftershock distribution. These new 3D fault representations are available as triangulated surface representations, and are being added to a Community Fault Model (CFM; Plesch et al., 2007, 2019; Nicholson et al., 2019) for wider use and to derived products such as a CFM trace map and viewer (Su et al., 2019).
\end{abstract}

\section{KEY POINTS}

- We present a 3D model of the source faults for the 2019 Ridgecrest, CA earthquake sequence.

- We employ an objective method of defining faults using hypocenter, focal mechanism, and geologic constraints.

- Source faults consist of two main segments, the Southern and Eastern Little Lake faults, and six large splays.

Supplemental Material

\section{INTRODUCTION}

Many of the fundamental aspects of earthquake science, including event nucleation, dynamic rupture and wave propagation, stress triggering, and other phenomena, are impacted by the properties of fault zones, including its location and geometry. Moreover, earthquake hazards assessments are largely based on inferences about the location and magnitudes of past and future earthquakes, which often involves defining the activity and slip rates on faults using geologic, seismologic, or geodetic observations. Among the most influential properties impacting earthquake phenomena and their associated hazards are source fault location and geometry. As a result, there have been many comprehensive efforts to map active fault zones in earthquake-prone regions. In California, these efforts began with the mapping of individual fault zones such as the San Andreas (e.g., Lawson et al., 1908; Allen, 1957; Dibblee, 1973). These efforts expanded to comprehensive mapping and classification of active fault traces with regional and national fault trace databases maintained by the California and U.S. Geological Surveys, respectively (Jennings and Bryant, 2010; see Data and Resources). In recent decades, these maps have been extended to develop 3D digital representations of

\footnotetext{
1. Department of Earth \& Planetary Sciences, Harvard University, Cambridge, Massachusetts, U.S.A.; 2. Seismological Laboratory, California Institute of Technology, Pasadena, California, U.S.A.

*Corresponding author: andreas_plesch@harvard.edu

Cite this article as Plesch, A., J. H. Shaw, Z. E. Ross, and E. Hauksson (2020). Detailed 3D Fault Representations for the 2019 Ridgecrest, California, Earthquake Sequence, Bull. Seismol. Soc. Am. 110, 1818-1831, doi: 10.1785/0120200053

(C) Seismological Society of America
} 
active fault systems in California (e.g., Seeber and Ambruster, 1995; Carena and Suppe, 2002; Shaw et al., 2002), and elsewhere (Plesch and Oncken, 1999). The Southern California Earthquake Center's (SCEC's) Community Fault Model (CFM) represents the most comprehensive of these efforts, including detailed 3D representations or more than 300 active fault segments that are deemed capable of generating moderate-to-large earthquakes (Plesch et al., 2007, 2016; Nicholson et al., 2019). Fault surfaces are defined in the CFM by a variety of data constraints, including geologic fault traces, earthquake hypocenters and focal mechanisms, well penetrations, and seismic reflection and refraction studies. The SCEC CFM is widely used in crustal deformation modeling, wave propagation simulations, earthquake simulators, and probabilistic seismic hazards assessment (e.g., Uniform California Earthquake Rupture Forecast, version 3 [v.3]). The CFM also directly contributes to other property modeling efforts, such as the development of 3D seismic-wavespeed models (e.g., Community Velocity Models; Magistrale et al., 2000; Süss and Shaw, 2003; Shaw et al., 2015) that are used in many aspects of seismology, including strong ground motion prediction.

Although the CFM has been shown to represent the significant majority of earthquake sources in southern California (Evans et al., 2020), it is by no means complete. Moreover, there is substantial uncertainty in the geometric representations of many fault zones given a lack of subsurface data. The 2019 Ridgecrest, California, earthquake sequence (Liu et al., 2019; Ross, Idini, et al., 2019; Chen et al., 2020; Hudnut et al., 2020; Ponti et al., 2020) is a clear example of the need to expand and refine these models. The $\mathbf{M} 6.4$ and 7.1 Ridgecrest earthquakes and their associated foreshocks and aftershocks occurred on faults broadly within the regional Little Lake fault zone associated with a series of highly segmented fault traces (Wills, 1988) with evidence of previous activity (Kozaci et al., 2019; Thompson Jobe et al., 2020). However, neither of the source faults, which we refer to as the eastern Little Lake fault (ELLF) and southern Little Lake fault (SLLF), were represented in the CFM.

This article describes our efforts to develop comprehensive, $3 \mathrm{D}$ representations of the Ridgecrest source faults. We employ an objective, reproducible method (Riesner et al., 2017) to model these fault geometries based on weighting constraints from mapped fault ruptures, earthquake hypocenters, and focal mechanism. Parts of the Ridgecrest sequence terminated into, or otherwise interacted with, other faults represented in the CFM, including the Airport Lake and Garlock faults. Thus, we sought to develop representations of the Ridgecrest faults that were compatible with these other CFM representations. We developed initial fault models in the days after the events (Plesch et al., 2019) and have subsequently refined these as the field mapping and earthquake catalogs have evolved. Here, we document these refinements to the Ridgecrest source fault representations and describe in detail how the improvements to the data constraints have impacted the latest fault representations.

\section{THE JULY 2019 RIDGECREST SEQUENCE}

The 2019 earthquake sequence occurred in the area of the northern Indian Wells Valley of eastern California, about $10 \mathrm{~km}$ northeast of the town of Ridgecrest (Fig. 1). This area is part of the eastern California shear zone (ECSZ), a tectonic system of distributed right-lateral shear that accommodates a component of relative Pacific and North American plate motion. In the past few decades, the ECSZ has sourced two major earthquakes, the 1992 M 7.3 Landers and 1999 M 7.1 Hector Mine events, with their epicenters located to the south of the Ridgecrest earthquakes in the Mojave Desert. In the decades prior to the 2019 Ridgecrest sequence, the Indian Wells Valley has experienced numerous earthquakes that are typically associated with swarms that extend over months (Hauksson et al., 1995). The largest events were the $1995 M_{\mathrm{L}} 5.4$ and 5.8 earthquakes. The 17 August $M_{\mathrm{L}} 5.4$ earthquake ruptured a north-south-trending fault and exhibited components of both normal and right-lateral motion. The 20 September $M_{\mathrm{L}} 5.8$ event ruptured a north-northwest-striking fault and exhibited right-lateral motion. Both events had thousands of aftershocks, and although no direct surface ruptures of these source faults were identified, both events produced triggered slip on the Airport Lake fault, which lies to the north of the epicentral zones (Roquemore and Zellmer, 1986; Hauksson et al., 1995).

The 2019 Ridgecrest sequence began with the 4 July M 6.4 earthquake, which occurred about $10 \mathrm{~km}$ northeast of Ridgecrest on a northeast-southwest-striking, left-lateral strike-slip fault (Fig. 1). The event had several moderate foreshocks (Huang et al., 2019) and an extensive aftershock sequence. The 5 July M 7.1 earthquake occurred about $34 \mathrm{hr}$ later and $7 \mathrm{~km}$ to the west of the $\mathbf{M} 6.4$ earthquake. The $\mathbf{M} 7.1$ event ruptured a northwest-southeast-striking fault and exhibited right-lateral strike-slip faulting (Liu et al., 2019; Ross, Idini, et al., 2019; Stewart et al., 2019; Chen et al., 2020; Hudnut et al., 2020; Ponti et al., 2020). The earthquakes produced extensive ground rupture along planes consistent with their preferred nodal planes and aftershock alignments (Kendrick et al., 2019). Notably, the two events are thought to have occurred on interpenetrating, nearly orthogonal fault systems (Barnhart et al., 2019; Ross, Idini, et al., 2019; Hauksson and Jones, 2020; Fig. 1). Both the main events occurred at about $8 \mathrm{~km}$ depth, with most aftershocks occurring above $10 \mathrm{~km}$ depth and some extending to about $12 \mathrm{~km}$ depth (Ross, Idini, et al., 2019) although for most of the mainshock rupture area, the aftershocks are generally shallower than $10 \mathrm{~km}$. The aftershocks for the $\mathbf{M} 7.1$ event extended about $30 \mathrm{~km}$ south of the mainshock epicenter and generally terminated at the Garlock fault. The northern termination of the rupture is characterized by a diffuse zone of aftershocks extending from about 8 to $25 \mathrm{~km}$ northwest of the mainshock 


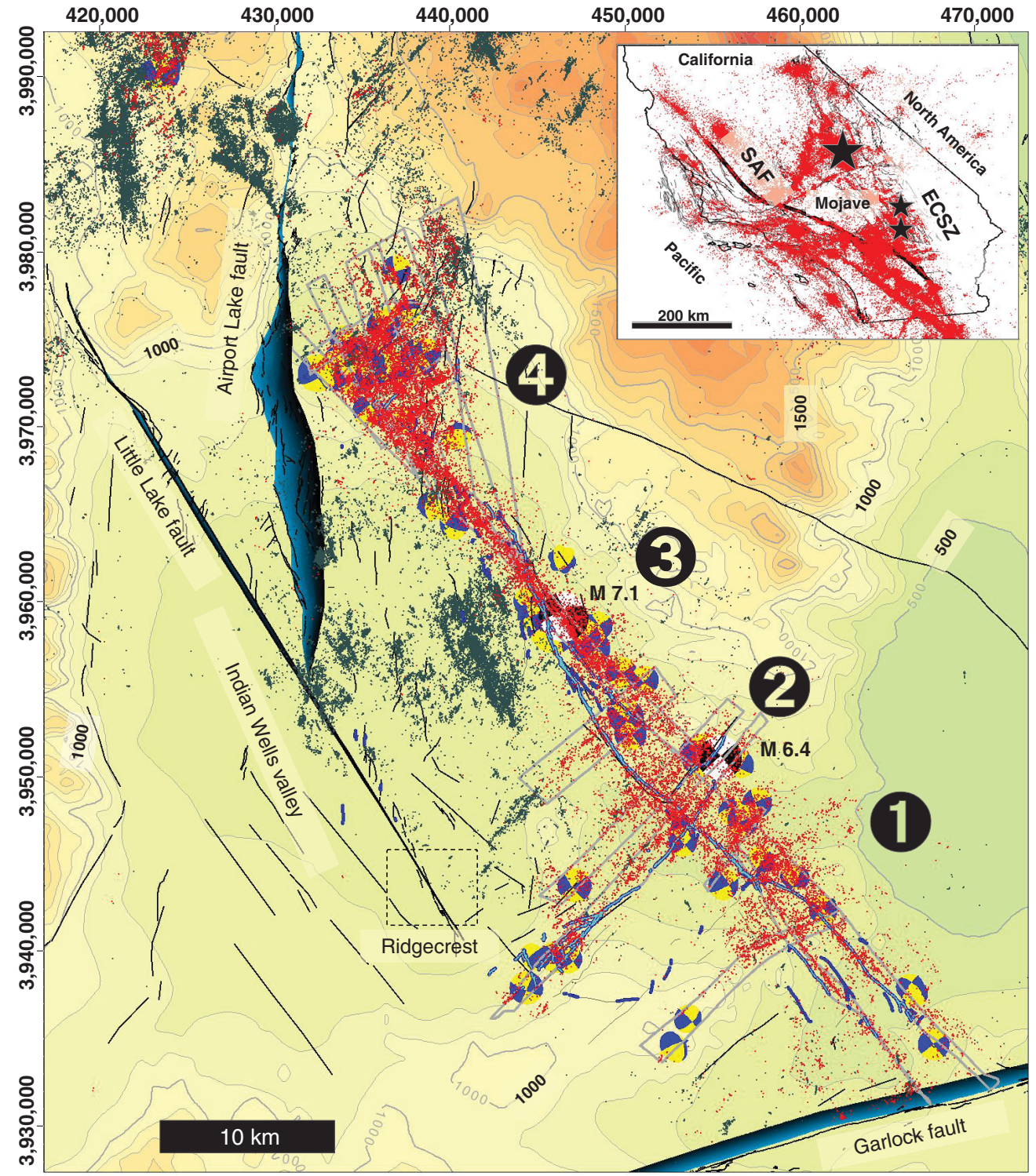

Figure 1. Map of the 2019 Ridgecrest sequence showing datasets used to constrain our 3D fault representations. Dots show epicenter locations: red events occurred after 1 July 19; gray events before. Blue traces are fault ruptures compiled by Kendrick et al. (2019); light blue traces are a subset of these used as constraints for fault surface interpolation. Black lines show fault traces from Qfault database (Quaternary fault and fold database [see Data and Resources]). Blue-black polygons are Community Fault Model representations of Little Lake, Airport Lake, and Garlock faults (Plesch et al., 2007, 2016; Nicholson et al., 2019). Focal mechanisms (upper hemisphere) are from the Southern California Earthquake Data Center (Hauksson et al., 2020); black-white circles are focal mechanism of mainshocks. Gray outlines show the fault surfaces modeled in this study for reference. Circled numbers refer to structural domains used in our analysis: 1, southern domain; 2, interaction domain; 3, central domain; 4, northern domain. Contour interval is $100 \mathrm{~m}$. Coordinates are for UTM zone 11N, North American Datum 1927 (NAD 27). (Inset) Location of event (large star), of the 1992 Landers and 1999 Hector Mine earthquakes (small stars), of the eastern California shear zone (ECSZ) and of the San Andreas fault (SAF). Red dots are relocated earthquakes from 1981 to 2019.

surface fault traces were generally short and discontinuous, and did not belie the rather planar, nearly continuous 15 and $45 \mathrm{~km}$ surface ruptures for the M 6.4 and 7.1 events, respectively (Kendrick et al., 2019). As noted, the earthquakes did not occur on a fault represented in the SCEC CFM. However, the M 7.1 mainshock ruptured a fault that is parallel to the Little Lake fault, with the M 6.4 event potentially providing a structural linkage between the two (Fig. 1). Thus, for our analysis, we will refer to the source faults for the M 6.4 and 7.1 events as the SLLF and ELLF, respectively.

\section{DATA AND METHODS}

We base our new 3D source fault representations of the 2019 Ridgecrest sequence on four principal datasets: (1) field mapping of rupture traces provided by Kendrick et al. (2019); (2) a relocated hypocenter cata$\log$ significantly expanded by quake template matching (QTM) methods (QTM catalog, provided by Ross for this study, through 25 July 2019); (3) a relocated hypocenter catalog that uses a regional set of stations to determine absolute locations (Hauksson et al., 2020); and (4) selected focal mechanisms provided by the Southern California Earthquake Data Center (SCEDC; Hauksson et al., 2020). The mapped trace of the rupture is based on thousands of field observations as well as on analysis of remote sensing data.

epicenter (Fig. 1). This region is bounded to the west by the Airport Lake fault zone.

Both the 4 and 5 July events occurred in a region where there were a series of mapped faults thought to exhibit Quaternary displacements (Wills, 1988). However, these
Only field confirmed trace data were used for our modeling effort. The first relocated hypocenter catalog contains more than 46,000 events, and was expanded from the Southern California Seismic Network (SCSN) catalog by sensitive template matching, allowing detection of events down to $\mathbf{M} 0.3$. The second 
(a)

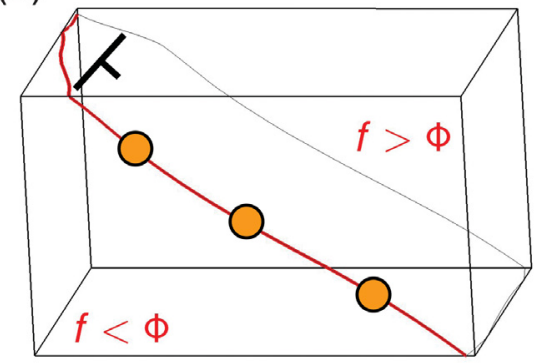

(b)

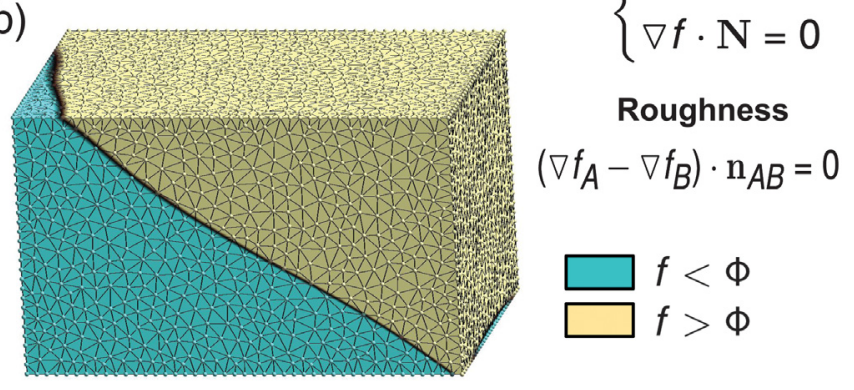

Figure 2. Constraint-based interpolation of fault representations. (a) Constraints used to interpolate a scalar $f$ in a volume. $u_{i}$ are the barycentric coordinates, $\alpha_{i}$ are the coordinates of nodes, and $\mathbf{N}, \mathbf{d}$ are the strike and dip vectors of orientation constraint Centered dots represent dot products (b) resulting field interpolated on the tetrahedral mesh. The fault surface corresponds to the constant value $\Phi$ of the variable $f$ (adapted from Riesner et al., 2017).

relocated catalog contains about 33,000 events of the sequence, extending up to 31 October 2019. Both catalogs clearly resolve internal structure to the rupture, including multiple splays for both the main ELLF and the SLLF. Our goal is to define the main, continuous splays of these two faults and other large ( $>5 \mathrm{~km}$ length) structures that are defined by the seismicity. (a)

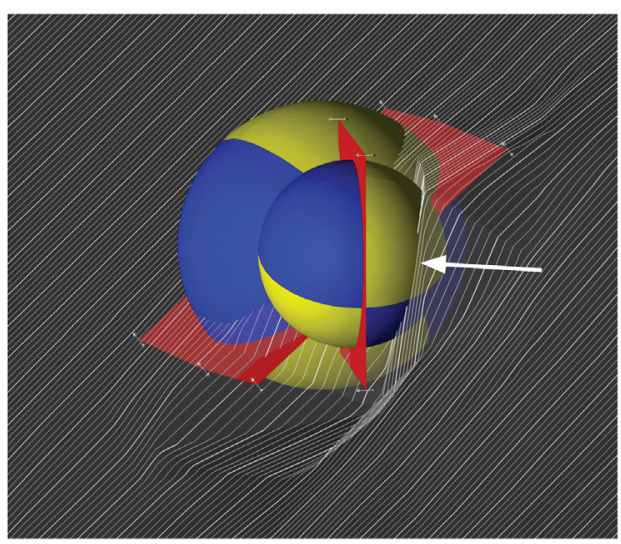

(b)

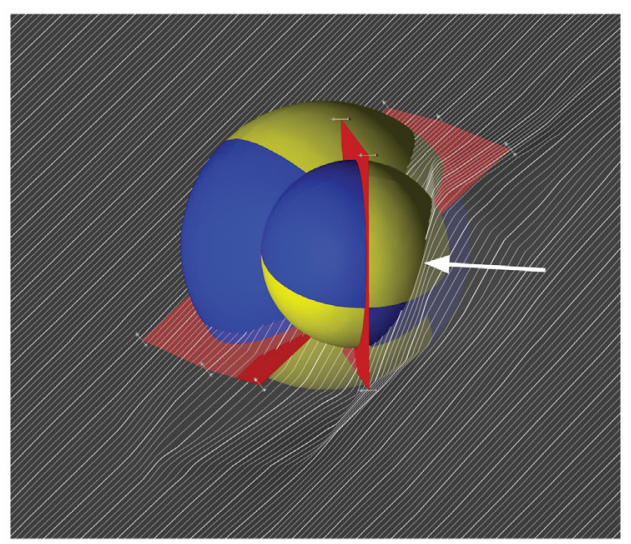

Figure 3. Example of how lowering the weight of orientation constraints (red nodal planes) adjusts the resulting modeled fault surface (white contours). (a) A weight of 0.5 ; (b) a weight of 0.1 . Arrow highlights the region of the fault surface that is affected most.
The earthquake sequence clearly illuminated other smaller fault segments, as well as distributed zones of seismicity around the main fault splays that we do not attempt to model. We incorporated all $\mathbf{M} 4$ and larger events listed by the SCEDC focal mechanism catalog in our analysis. We assumed that the fault plane is locally parallel to one of the nodal planes.

The method we use to interpolate and fit 3D surfaces to the data is presented by Riesner et al. (2017). This fault modeling approach is based on constraining a scalar field in a meshed box volume, the interpolation mesh, finding a best $3 \mathrm{D}$ fit to the constraints, and then extracting a fault representation as an isosurface from the scalar field (Fig. 2; Frank et al., 2007). Three constraints are implemented in our workflow. The first is used to fit a surface to $3 \mathrm{D}$ point locations (e.g., traces or hypocentral locations), and the second one to locally fit to a 3D orientation based on nodal planes. A third constraint controls overall roughness of the fault surface by limiting the gradient of the scalar field to a constant between neighboring regions. This constraint is necessary, in practice, to allow for converging solutions. All constraints can be weighted. For a given fault segment, we typically apply a weight to the collection of all hypocenters that is similar to the summed weight of all points along the field-mapped surface trace. The orientation constraint naturally has a larger impact on fault-plane regions that are closer to the location of the constraint. Because the focal mechanism catalog lists event locations that are not always consistent with locations in relocated catalogs, we generally assign relatively lower weights to orientation constraints. Figure 3 shows the effect of varying the weight of these orientation constraints. For the gradient constraint, we use a constant weight of 0.1 that effectively serves as a baseline for all other weights. The final fitting is a discrete-smooth interpolation (DSI; Mallet, 1992) of the scalar field that iteratively minimizes residuals to the constraints in a least-squares sense. Computationally, the interpolation is efficient and only takes a few seconds on standard desktop PC to converge.

The modeling workflow consists of a series of defined steps that can be iterated and reproduced given changes to input data and workflow parameters such as the weighting of constraints (Fig. 4). The first step involves collecting the input data to model an identified fault. Input data typically include the surface rupture trace and a selection of hypocenters that show alignment with the rupture trace and focal mechanism nodal planes in the 


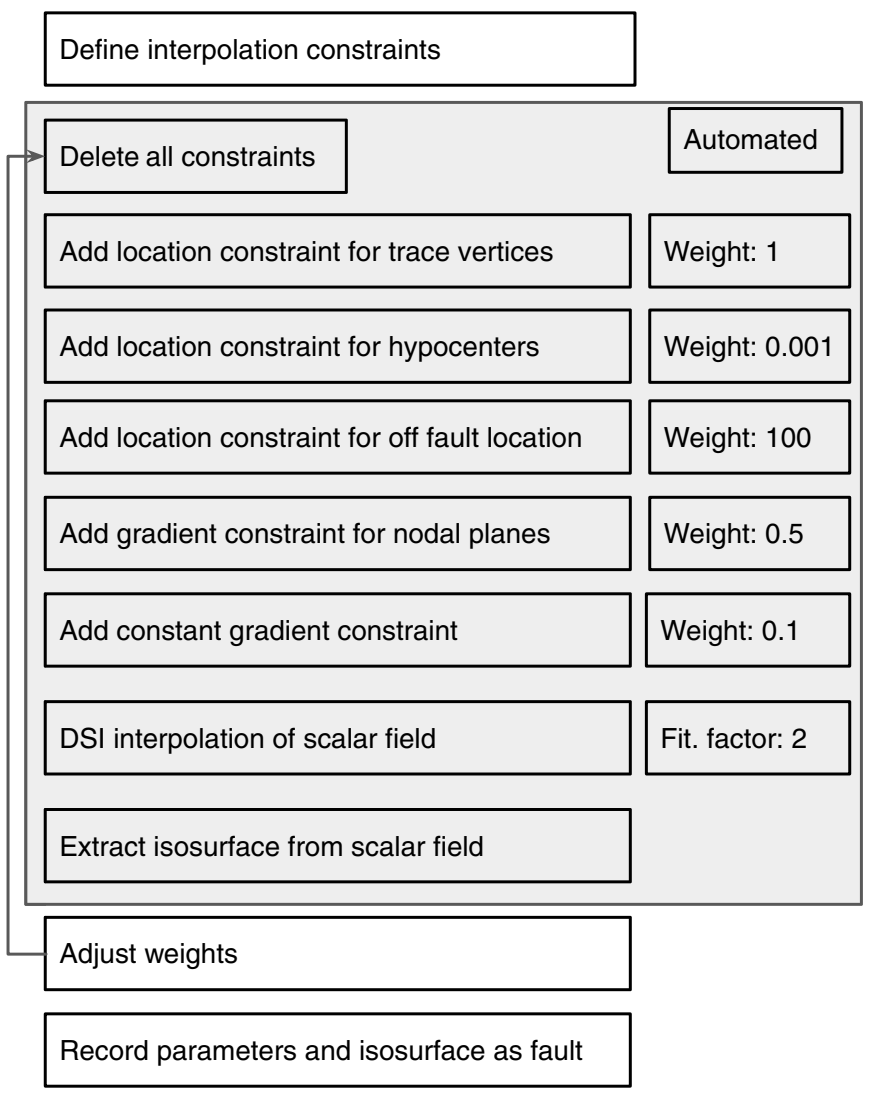

Figure 4. Steps of the workflow designed to be partially automated (gray box) with input of typical weights. Automation does not include the selection of the various constraints. The constraint selection criteria for each fault are described in the main article. DSI, discrete-smooth interpolation.

vicinity of these hypocenters. Not all modeled faults show surface rupture. Rather, such faults are recognized from subplanar alignments in the hypocentral distribution. This initial determination is typically accomplished by visual inspection of the data. We found use of a fully $3 \mathrm{D}$, geoscience-focused, and integrative modeling environment (Emerson GOCAD/SKUA), efficient for this purpose. Subsequently, this process of identifying faults illuminated by seismicity can be refined by a statistical analysis of the distances between hypocenters and a modeled 3D fault surface.

After collecting all input data, the interpolation constraints are defined. Location constraints are typically defined first. However, the order in which these constraints are defined is generally not significant. The vertices of the polylines that make up the rupture trace often represent one location constraint. Connectivity between vertices is not considered. In addition, for numerical stability, it is necessary to have at least one vertex as a location constraint with a different scalar value than the constant target value for the fault. Conceptually, this off-fault location establishes an initial gradient that then can be perturbed to fit the main constraints. This single vertex constraint is defined at the mesh perimeter. However, its exact location is not important for the final fault geometry in the space where the fault is defined by other constraints. The next distinct location constraints are the hypocentral locations selected for the fault. These can be assigned a weight different from that of the fault trace locations. The weight given is per hypocenter. In principle, it would be possible to vary the weights for each hypocenter or groups of hypocenters by considering, for example, moment release, location uncertainty, or distance from an initial model fault. While we will explore this possibility, we found that the parameter space is sufficiently large to arrive at solutions that match observations by assigning the same weight to all hypocenters. After the location constraints are defined, the orientation constraints are provided using nodal planes of collected focal mechanisms. The orientation constraint is given in terms of a gradient control vector. This vector controls the direction of the local gradient of the scalar field during the interpolation. We choose to use only direction control with this constraint, without considering the magnitude of the gradient or its polarity. This choice addresses the potential mismatch of locations of focal mechanisms and of the hypocenter for the same event. As a practical matter, we use the normal vectors of a disk representing the nodal plane as the gradient control vector, at the vertices of a polygon at the circumference of the disk. There are multiple such normal vectors (eight in our representation) for each nodal plane that we account for by lowering the weight per vertex constraint proportionally. As the final constraint, a global constant gradient constraint is defined, which is applied throughout the interpolation volume and is not tied to a location. This constraint is used during the interpolation to keep the variation in gradient small between neighboring regions, in effect controlling overall roughness.

After all constraints are set up, a DSI (Mallet, 1992) interpolation of the scalar field is performed, using a matrix formulation (Muron et al., 2005), with a fitting factor of 2, unlimited numbers of iterations, and a convergence error of $10^{-7}$. The fitting factor is a trade-off between overall smoothness and fit to given constraints. The fault geometry is implicitly defined by the scalar field as an isosurface of the target value given for the constraints (Fig. 2, we use zero as the target value for the isosurface). We use standard extraction of the isosurface at all edges of the tetrahedra that constitute the interpolation mesh to generate a triangulated surface of the modeled fault. As an isosurface, the fault surface is defined for the complete interpolation volume. Because the interpolation volume encompasses an enlarged region surrounding the complete earthquake sequence, defining the lateral and vertical limits of a fault becomes a separate, next step. For the upper vertical limit, we use topography for faults that have a rupture trace and the upper limit of seismicity for faults, which did not rupture the surface. The lower vertical limit is provided by the regional base of seismicity surface, which is used to limit 


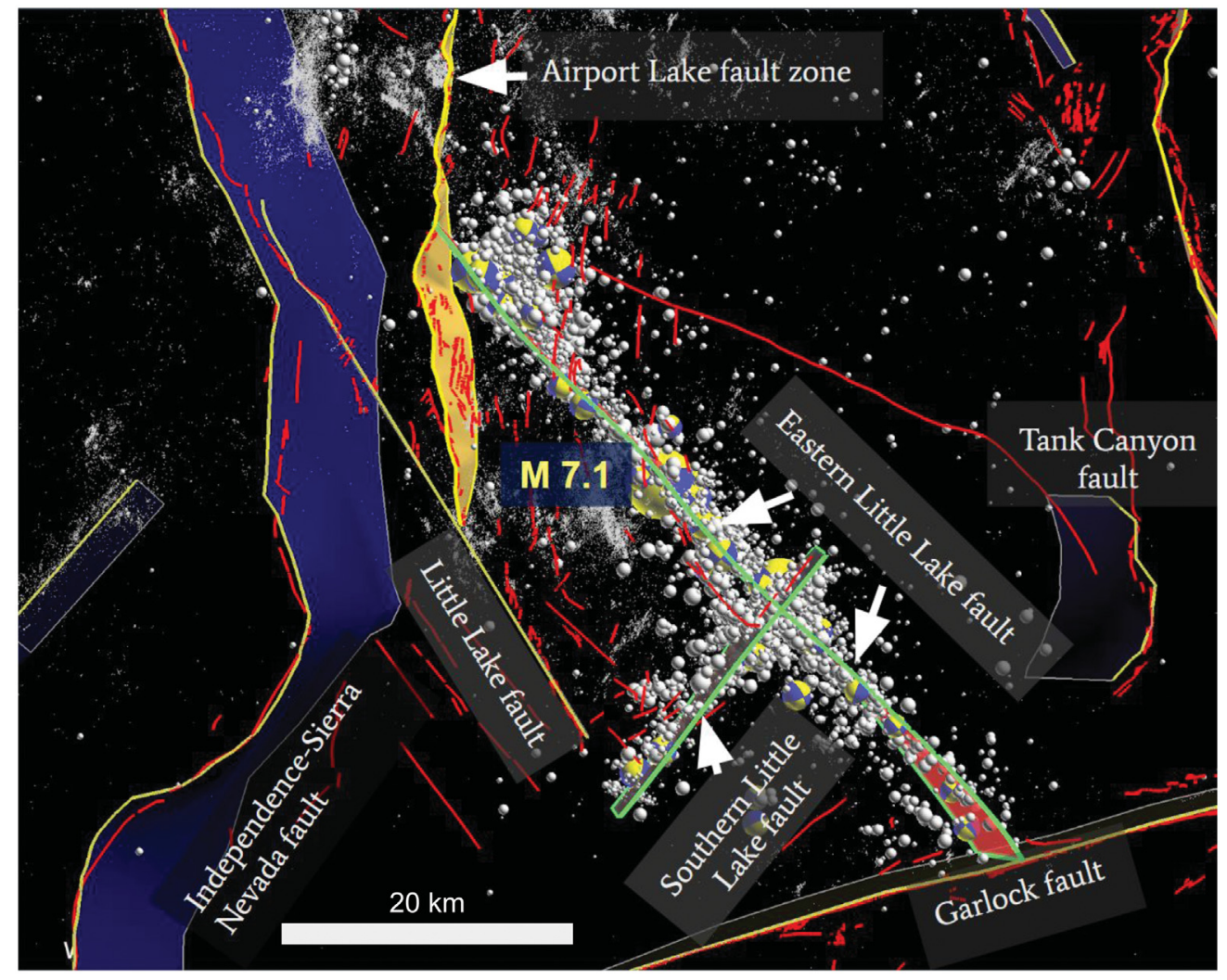

Figure 5. Initial, simplified 3D source fault geometry developed in the weeks following the earthquake sequence (Plesch et al., 2019). orthogonal southwest-northeast, and, assigned all hypocenters and nodal planes in each trend, as constraints in the workflow. This rapid procedure resulted in two contiguous $3 \mathrm{D}$ fault planes that proved very useful for communicating the overall structure to the community and for placing it into the context of the CFM (Plesch et al., 2007) and Qfault databases (see Data and Resources). These generalized fault planes also serve as a reference to define the additional structure our more detailed analyses described later was able to resolve.

In this initial representation, the ELLF is fairly linear and subvertical, extending from the Garlock fault in the south to the Airport Lake fault in the north. The SLLF is also fairly linear and subvertical, and crosses and is orthogonal to the ELLF.

the depth of the CFM (Nazareth and Hauksson, 2004; Plesch et al., 2007). The lateral fault limits are either given by other faults, such as the Garlock and Airport Lake faults, or by the extent of seismicity.

The workflow is currently implemented using the StructureLab plugin (Caumon et al., 2019, Research for Integrative Numerical Geology [RING] group at École Nationale Supérieure de Géologie, France) for Emerson/ Paradigm SKUA/GOCAD and a small macro assembling the necessary steps in a convenient manner, allowing for rapid iterations. We use manual iterations to fine-tune weighting within the ranges outlined earlier.

\section{INITIAL, NEAR-REAL-TIME INTERPRETATION}

In a rapid response to the earthquake sequence, we used the workflow outlined earlier to generate a representation of the 3D source fault geometry (Fig. 5; Plesch et al., 2019). This analysis incorporated a very limited dataset, consisting of SCSN catalog locations (Hutton et al., 2010) from the first four days of the sequence and focal mechanisms of $\mathbf{M} 4$ and larger events. Field mapping was not yet available.

Our goal was to define the main rupture planes associated with these earthquakes, and we did not make an attempt to resolve subsidiary fault splays in more detail. As such, we identified two trends, the main southeast-northwest trend and the

\section{DEVELOPING DETAILED FAULT REPRESENTATIONS}

To develop a more detailed representation of the 2019 Ridgecrest source faults using the complete set of high-quality hypocenter locations and detailed rupture trace maps, we divide the rupture into a number of structural domains defined by rupture trace and seismicity patterns along the ELLF and SLLF (Fig. 1). These include (1) a southern domain, where two subparallel faults are mapped, consisting of an eastern and western branch. We represent the eastern branch as part of a continuous, main ELLF (south section) and the western branch as a splay (west splay); (2) a complex zone of interacintersect and interpenetrate one another. We subdivide the SLLF into subparallel strands consisting of a shorter, northern segment and a main, southern strand; (3) a central domain, which includes the $\mathbf{M} 7.1$ mainshock epicentral zone. The ELLF in this region consists of the main strand to the west, and an eastern, more limited branch. The eastern branch is apparent in the mapped field rupture traces and distinguished by an intervening gap in seismicity; and (4) the northern domain, where distributed seismicity including a large number of $\mathbf{M} 4$ plus events define a number of subparallel faults that trend obliquely with respect to the main ELLF trend, as well as a number of cross faults. We represent this domain by tion between the ELLF and SLLF. Faults in this region generally 
(a)

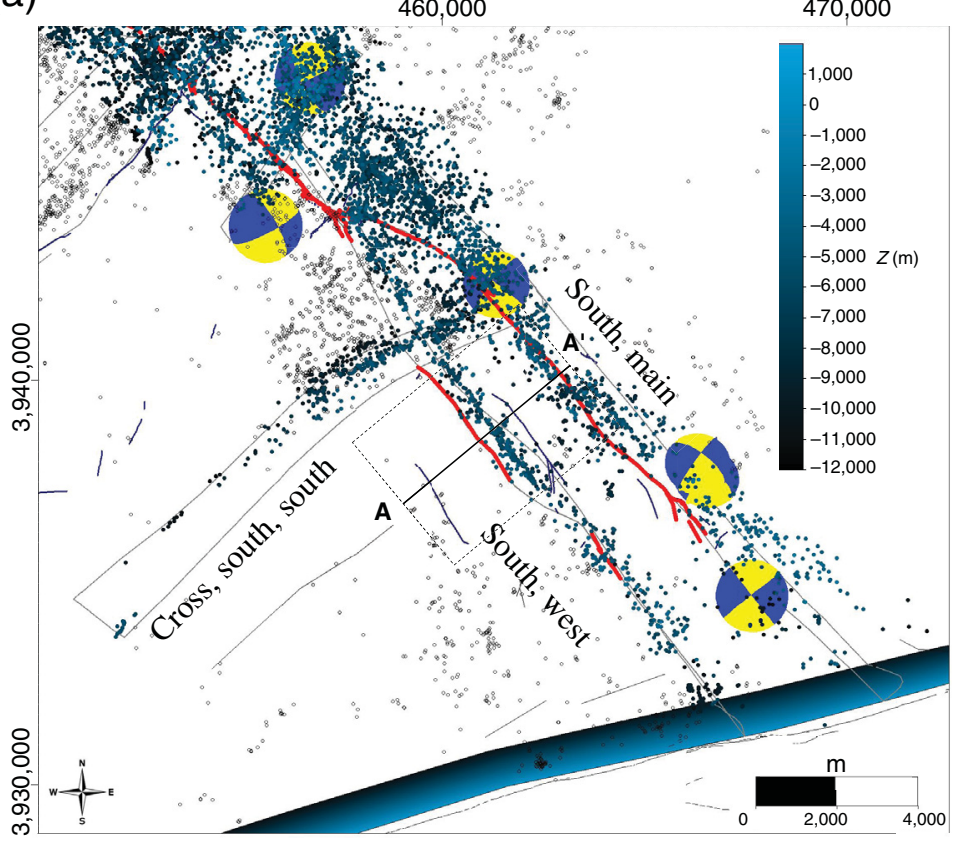

(c)

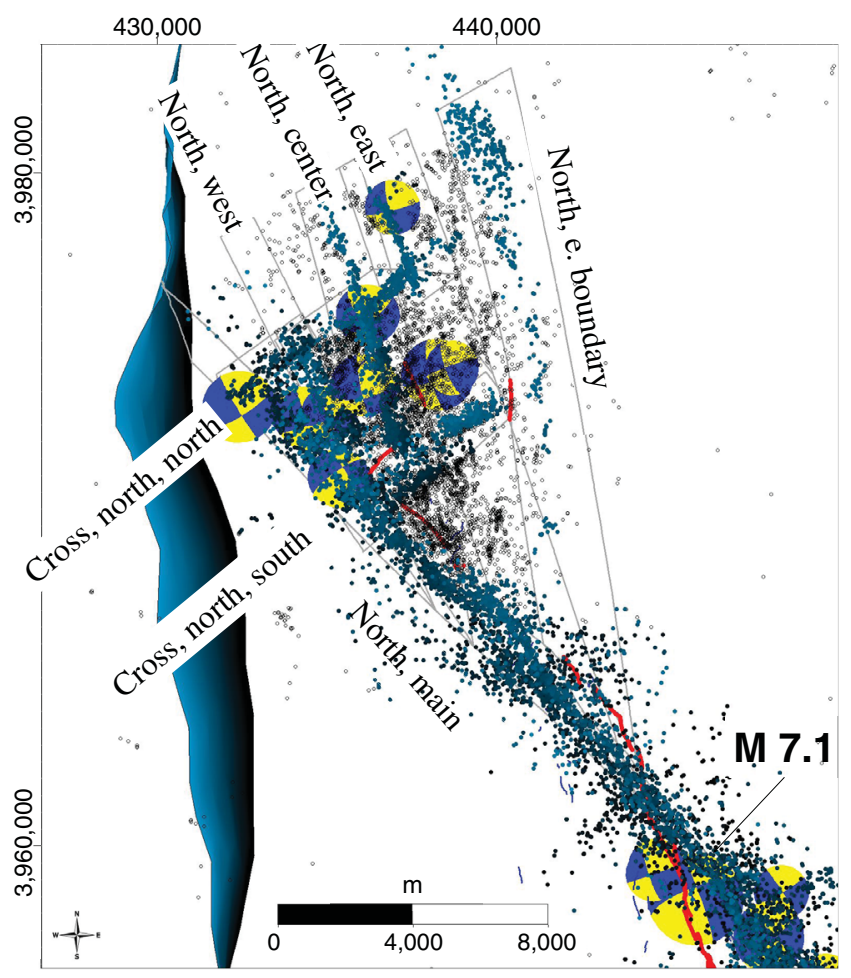

(b)

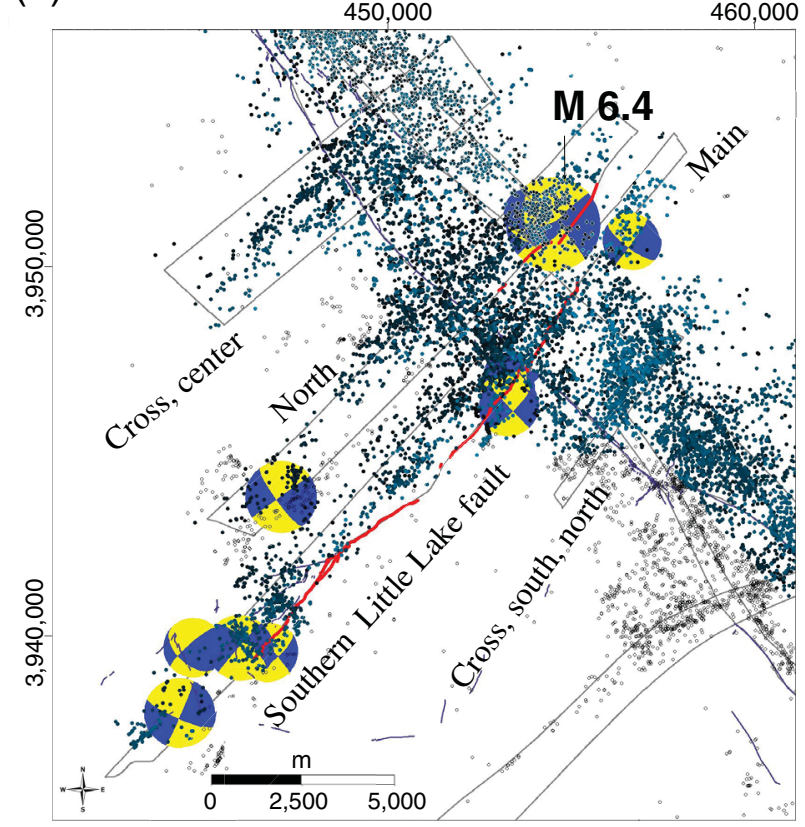

(d)

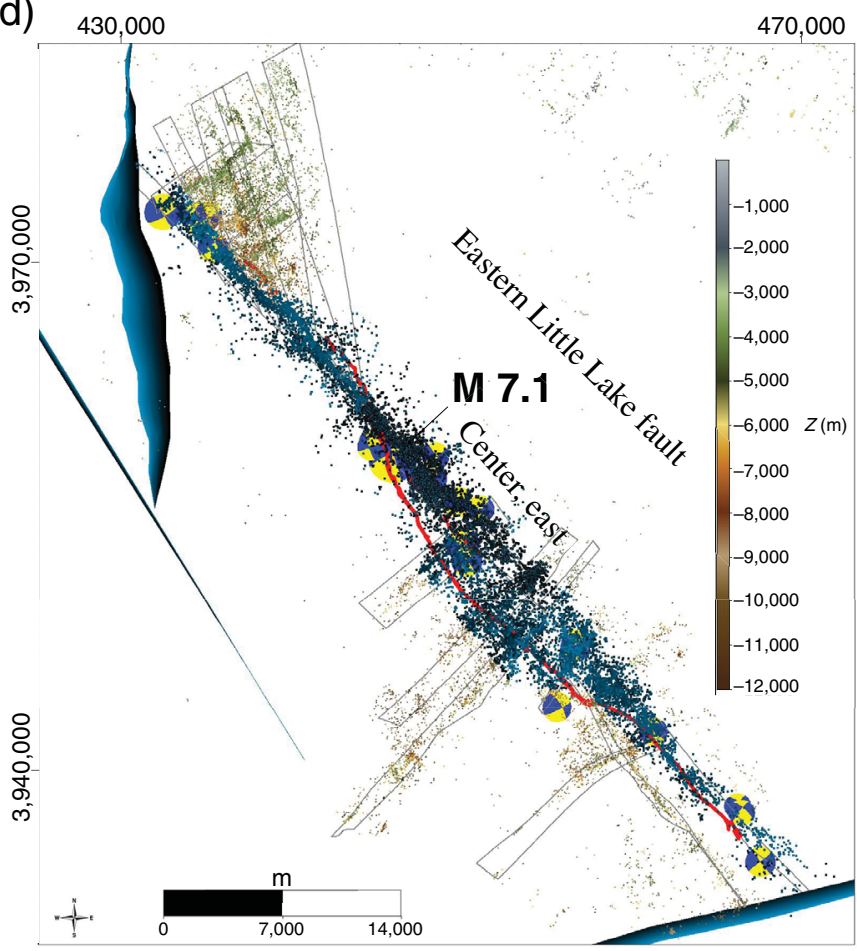

describing the four main seismicity lineaments as discrete faults. In addition, there are a number of small cross faults throughout all four domains of which we represent the six largest: two in the southern domain, one in the central domain, and three in the northern domain.

Having identified distinct structural domains from rupture trace and seismicity patterns, we separated input data for each of the 14 identifiable faults and applied the modeling workflow. We first model the main strand of ELLF (Fig. 6d) by selecting the most continuous traces mapped in the field along the
Figure 6. Maps showing data used as constraints for the modeled faults: (a) southern area of eastern Little Lake fault (ELLF); (b) central area with intersection of southern Little Lake fault (SLLF) and ELLF; (c) northern area of ELLF; and (d) main strand of ELLF. Blue dots represent hypocenters, circled in $(b, d)$ to distinguish constraints for eastern splay of the ELLF, central section; red traces are field-mapped sections; yellow-blue circles are focal mechanisms (upper hemisphere projection), with the nodal plane that is the closest to the fault trend used as constraint. Black circles in $(a-c)$ and colored circles in (d) are hypocenter not used as constraints. Color bars show depth scale. Coordinates in UTM zone 11N, NAD 27 coordinates. 
southeast-northwest trend. We then added smaller, more disconnected traces in the northern structural domain that corresponded with the main trend of the fault. The selected trace supplies about 12,000 vertices as constraints input. We then identified 19 focal mechanisms, including the M 7.1 mainshock, along the same trend. We extracted the nodal plane from each focal mechanism following that trend. The selection of hypocenters for this fault occurred in three phases of continued refinement. The first selection included about 33,000 events in a 6-kilometer-wide band along the trend, excluding events in the southern branch previously identified. In two subsequent phases, this selection was trimmed to about 14,000 events by excluding clusters of events that separated from the main fault trend and thus used as input data for other modeled fault splays. Most of these excluded events were located in the diffuse seismicity of the northern domain. The final set of constraints results in a 60-kilometer-long fault surface that is generally steeply dipping but changes from a moderate northeast dip in the southern $\left(75^{\circ}\right)$ and central $\left(55^{\circ}\right)$ domains to a steep southwest dip $\left(85^{\circ}\right)$ in the northern domain. Below about $6 \mathrm{~km}$ depth, the fault becomes nearly vertical. With 14 out of the 19 nodal planes within $1.5 \mathrm{~km}$ from the fault, the fault surface is locally curved, with mean local curvatures reaching a maximum of 0.001 . The smoothness of the shallow fault geometry is controlled by the trace and exhibits comparable amounts of mean curvature.

As previously described, we modeled two faults branching from the main strand of the ELLF. In the southern domain, this includes a western branch (Fig. 6a) for which three segments of rupture traces were selected corresponding to about 2000 vertices. Along the trend of this trace, we selected about 1000 hypocenters of aligned events that are clearly separated from the main trend of seismicity by a gap of about $2 \mathrm{~km}$ width. For this splay, there is an increased number of events in the QTM catalog that have a strong planar alignment. These hypocenters show clearly that there is a single, steeply dipping fault plane at seismogenic depths (Fig. 7). We used this alignment from the QTM catalog for selection of events in our regional catalog in a box with the same dip as the alignment. No nodal planes were available as input constraints for this fault segment. The resulting fault surface (western segment of the ELLF, south section) is about $14 \mathrm{~km}$ long, closely follows the rupture trace, and is moderately northeast dipping $\left(75^{\circ}\right)$ in the upper $2.5 \mathrm{~km}$. At depth, the surface turns subvertical. Thus, both the western and main segments of the ELLF are essentially parallel.

The second, modeled branch of the main ELLF is situated in the central domain, about $3 \mathrm{~km}$ to the east of the main fault strand (Fig. 6b). The selected trace consists of two main segments, defined by 1800 mapped vertices. The gap in hypocenters that separates the branch from the main fault follows moderately dipping plane, and is therefore not apparent in map view. This planar orientation also connects hypocenters best to the discontinuous surface trace. Therefore, we used this

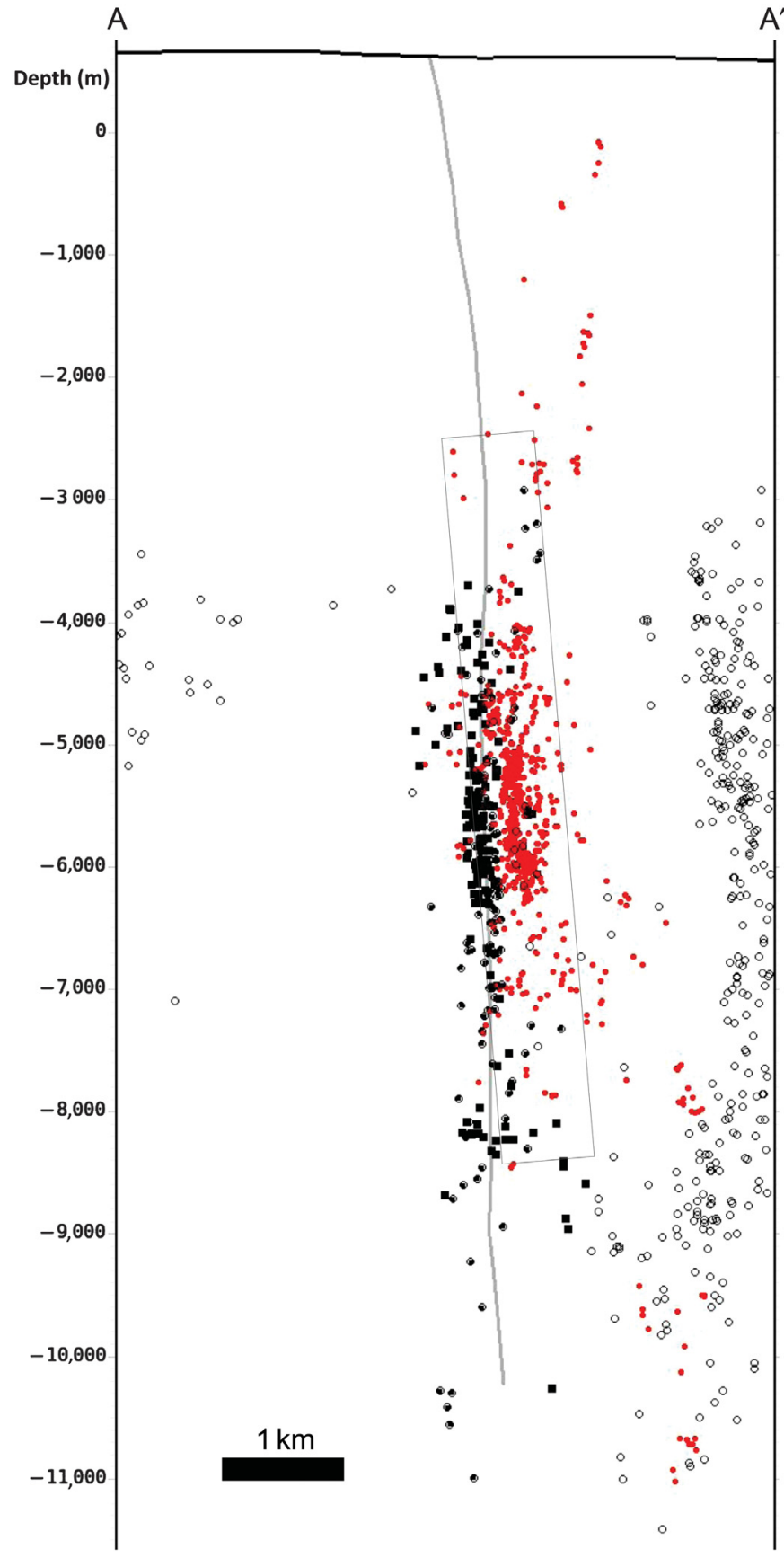

Figure 7. Cross section $A-A^{\prime}$ (see Fig. 6a for trace location and projection box) shows planar alignment of hypocenters in quake template matching catalog (red) for western splay of the ELLF, southern section (gray line). Hypocenters in regional catalog are black, including both open and solid circles. Solid black events were used constraints for modeling the fault.

orientation to select hypocenters for input constraints for modeling the fault surface. There are 3400 events associated with this fault segment. The continuity of seismicity along the trend does not indicate lateral terminations or segmentation of this branch. We therefore terminate this branch with the main strand of the ELLF to the north and by the northern strand 
of the SLLF (described later) to the south. For orientation constraints, we used nodal planes of nine focal mechanisms that lie along the trend. The resulting fault surface is about $13 \mathrm{~km}$ long, dips about $75^{\circ}$ in the upper $6 \mathrm{~km}$, and is nearly vertical at depth. We note that the modeled branch maintains separation from the main strand at depth.

In the northern domain, we model four faults that are oblique to the northern section of the ELLF: the western, central, eastern, and eastern boundary faults (Fig. 6c). These are primarily defined by seismicity lineaments that all share a similar trend and steep dip to the northeast. Because of this dip, the epicenters are rather distributed in map view but can be readily identified and distinguished in an inclined view down the dip direction. The selected constraints include about 1000 events for the western, about 1000 events for the central, about 300 events for the eastern, and about 400 events for the eastern boundary fault. There are only a few surface rupture traces along these faults. The eastern and the eastern boundary fault each has a shorter trace of 1-2 km length resulting in less than 20 mapped vertices used as location constraints. Orientation constraints are provided by nodal planes of five, four, and two focal mechanisms for the western, central, and eastern faults, respectively. The northern limit of all faults in the northern domain is the limit of aligned seismicity. To the south, all faults extend in a generalized fashion to the main strand, which we used to truncate them. The resulting fault representations have increasing lengths from $7 \mathrm{~km}$ for the western fault, to $20 \mathrm{~km}$ for the eastern boundary fault. They are subparallel, dipping about $80^{\circ}-85^{\circ}$ to the northeast, throughout the seismogenic crust.

In the northern domain, we additionally represent three faults that trend at a high angle to the main trend, for example, southwest-northeast (Fig. 6c). We use the term "cross faults" to describe structures with this trend. These cross faults are primarily defined by seismicity lineaments with closely corresponding trends and steep dips to the southeast. The northern and north-central cross faults of the ELLF, northern section, are constrained by 200 events and by 700 events, respectively, clustering along steeply southeast-dipping planes, at the northernmost limit of the rupture. The southern cross fault is constrained by 800 events aligned along a steeply southeastdipping plane, as well. This plane projects upward into a small, 2-kilometer-long surface rupture trace with about 50 mapped vertices, which provide location constraints. No focal mechanisms were available as orientation constraints. The lateral extents of these cross faults are defined largely by the extent of aligned seismicity. This results in an en echelon, right-stepping arrangement of the northern and north-central cross faults, with the northern cross fault interpenetrating the main strand of the ELLF to the west, and north-central fault being truncated by the eastern splay fault of the northern section of the ELLF to the east. The resulting, combined length of the fault representations is about $6 \mathrm{~km}$, with a dip of about $85^{\circ}$ to the southeast. For the southern cross fault, the workflow results in an about 6-kilometer-long representation, dipping about $80^{\circ}$ to the southeast in the upper $8 \mathrm{~km}$, and $85^{\circ}-90^{\circ}$ at depth. The southern cross fault also interpenetrates the main strand of the ELLF to the west, and crosses the eastern splay fault of the northern section of the ELLF to the east.

In the central domain, we represent one cross-fault (Fig. 6b) that is well defined by hypocentral alignment. Hypocenters there align in a band a few hundred meters in width along a moderately northwest-dipping plane. This band contains about 700 events that define location constraints. No surface rupture trace or focal mechanisms were available as further constraints. The lateral extent of this cross fault is defined by the extent of the seismicity. To the north, the band of seismicity associated with this cross fault can be clearly followed across the main strand of the ELLF, and then truncates against the eastern branch of the ELLF, central section. Because no rupture trace was mapped at the surface, the cross fault is considered blind. This fault representation is vertically limited to the depth range of selected hypocenters. Application of the workflow results in a 7-kilometer-long fault representation, which dips $77^{\circ}$ to the northwest, consistently throughout the entire depth range. The upper tip line is at about $2.5 \mathrm{~km}$ below sea level.

The southern domain exhibits two additional cross faults that we represent-a northern (Fig. 6b) and southern cross fault (Fig. 6c) of the ELLF, southern section. All are primarily defined by hypocentral lineaments. The southern hypocentral alignment dips to the northwest, in the same direction as most of the cross faults in other regions of the rupture appear to. There is some steepening of the dip with depth. The northern hypocentral alignment, however, dips steeply to the southeast. Selecting events for each dipping alignment generates about 400 hypocentral location constraints for both the northern and southern cross fault. No surface rupture trace and no focal mechanism were available as further constraints. Therefore, the upper limit of the faults is defined by seismicity. Laterally, the northern cross fault is limited by the extent of associated seismicity that crosses the main strand of the ELLF. The southern cross fault does not clearly cross the main strand at its eastern limit and has sporadic seismicity extending for about $6 \mathrm{~km}$ to its western limit. The resulting representations for the northern and southern cross faults are 6 and $12 \mathrm{~km}$ long, respectively, and dip about $85^{\circ}$ to the southeast and $75^{\circ}$ above $4 \mathrm{~km}$ to $85^{\circ}$ at depth to the northwest, respectively.

After modeling the ELLF, we collected input data for the southern, main strand and the northern strand of the SLLF (Fig. 6b). This included the initial M 6.4 mainshock, which is located in the area where the fault interacts with the ELLF. A preliminary analysis using distance measurements of hypocenters to the initial, rapid response representation of the SLLF as a single surface revealed a bimodal distance distribution (Fig. 8). This observation is best explained by the existence of a northern, parallel strand. The main strand is defined by a 13-kilometer-long, very continuous surface trace that 
(a)

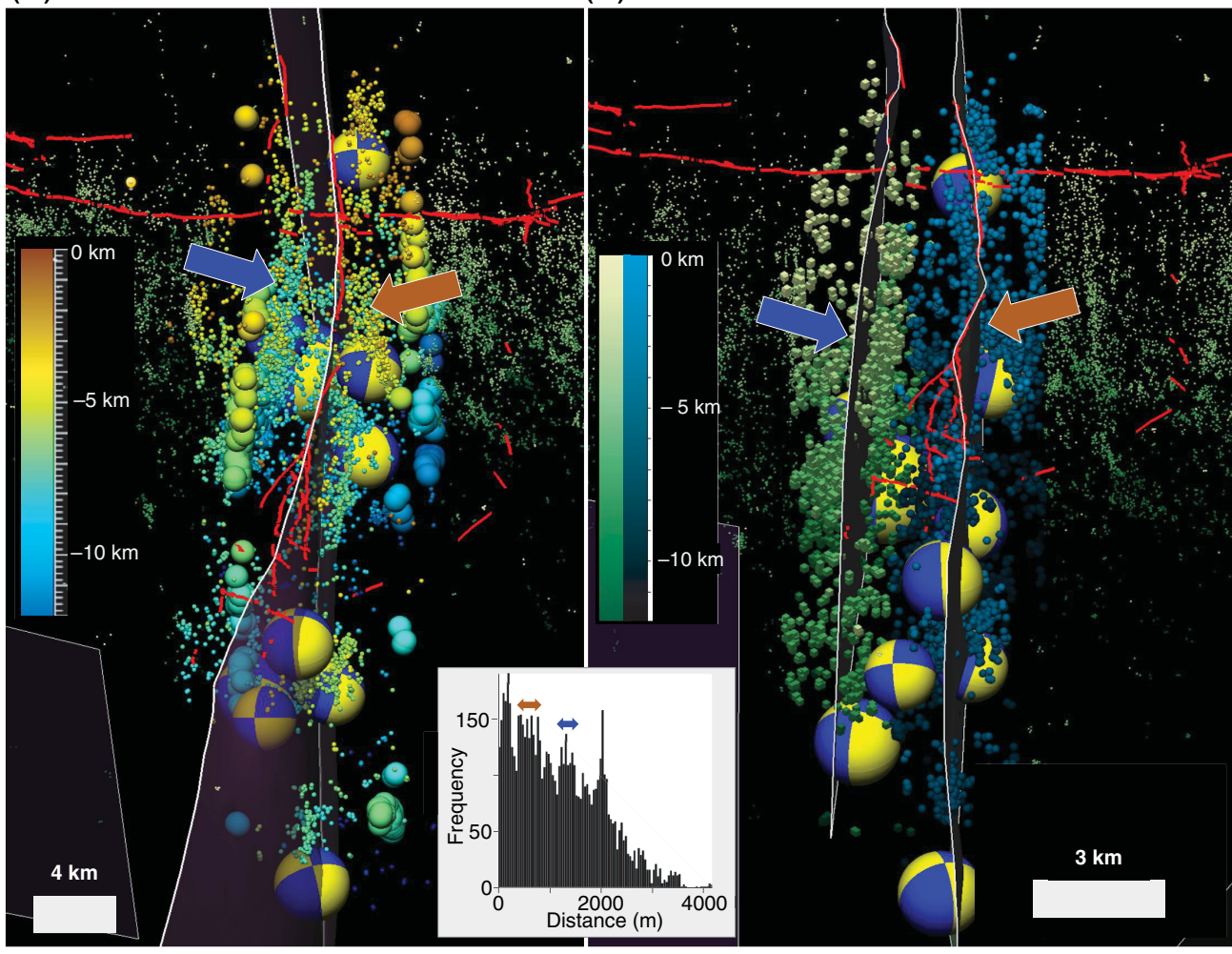

Figure 8. Example of how distance analysis (histogram) of (a) an initial, single-modeled fault surface reveals additional modes (arrows on histogram), which are then used to define (b) additional fault surfaces. Colors show depth of hypocenters. Shown focal mechanisms were selected for fault construction.

ruptures representing the SLLF and ELLF and 12 additional fault splays (Fig. 9). The main SLLF, associated with the 4 July 2019 M 6.4 earthquake, extends for about $20 \mathrm{~km}$ in a northeast-southwest direction. The fault is steeply dipping $\left(\geq 80^{\circ}\right)$ but is nonplanar, with components of northwest and southeast dip at various locations along strike. A second fault splay lies about $3 \mathrm{~km}$ to the northwest and trends parallel to the source fault we defined for the M 6.4 event. This second, northern fault splay extends for about $18 \mathrm{~km}$ along strike, and is defined by hypocenters, focal mechanisms, and surface ruptures along the eastern extent of the fault trace. Three additional northeastsouthwest-trending cross faults are modeled to the north and south of the SLLF. These faults are defined by planar alignments of seismicity, and perhaps represent the largest of a

crosses the ELLF in the northeast and splits into several splays in the southwest. We selected all trace segments that are defined by 1800 vertices and use those as location constraints. There is a clear trend in seismicity that follows the strike of the surface rupture and dips steeply to the northwest. The trend can be followed across the main trend of the ELLF, along with the surface trace. About 2000 hypocenters were defined as constraints for this fault. Nodal planes of seven focal mechanism, including of the $\mathbf{M} 6.4$ mainshock, were also available as orientation constraints. The northern strand is largely defined by a parallel trend in hypocenters, a short (4-kilometer-long) surface rupture trace, and three nodal planes. The alignment in hypocenters of the northern strand has a central area with a reduced density of seismicity, but nevertheless appears to represent a single, continuous fault segment. As lateral limits of the fault, we use the extents of the seismicity trends. Using these constraints as input to the workflow results in a 21-kilometer-long main strand and a 15-kilometer-long northern strand, both dipping about $85^{\circ}$ to the northwest.

\section{DISCUSSION}

Our 3D source fault model of 2019 Ridgecrest earthquake sequence defines a complex system, consisting of two main distributed system of cross faults that ruptured in the earthquake sequence.

The source fault representation for the 5 July $\mathbf{M} 7.1$ earthquake consists of an $\approx 60$-kilometer-long, northwest-southeast-striking plane that we define as the ELLF. The fault surface is illuminated by seismicity along most of its extent, whereas ground surface ruptures are generally limited to the central ( $\approx 40$-kilometer-long) portion of the rupture. The fault dips steeply $\left(\geq 55^{\circ}\right)$ to the northeast in the center and along the southern extent of the rupture, and steepens to near vertical along the northern extent of the rupture. The fault becomes near vertical at depth along the entire extent of the rupture. This pattern has been proposed as a general characteristic of strike-slip faults owing to the larger confining stresses and more systematic orientation of principal stress at depth (Harding, 1973; Sylvester, 1988). Moreover, the ELLF consists of two distinct subparallel splays to the south of the $\mathbf{M} 7.1$ mainshock epicentral zone. The M 7.1 mainshock is associated with the western (main) fault splay. However, many of the larger foreshocks and aftershocks are associated with the eastern of these two fault splays. This eastern splay merges with the western splay to the north, but to the south appears to truncate into the northern splay of the SLLF. In contrast, the western segment of the ELLF passes 


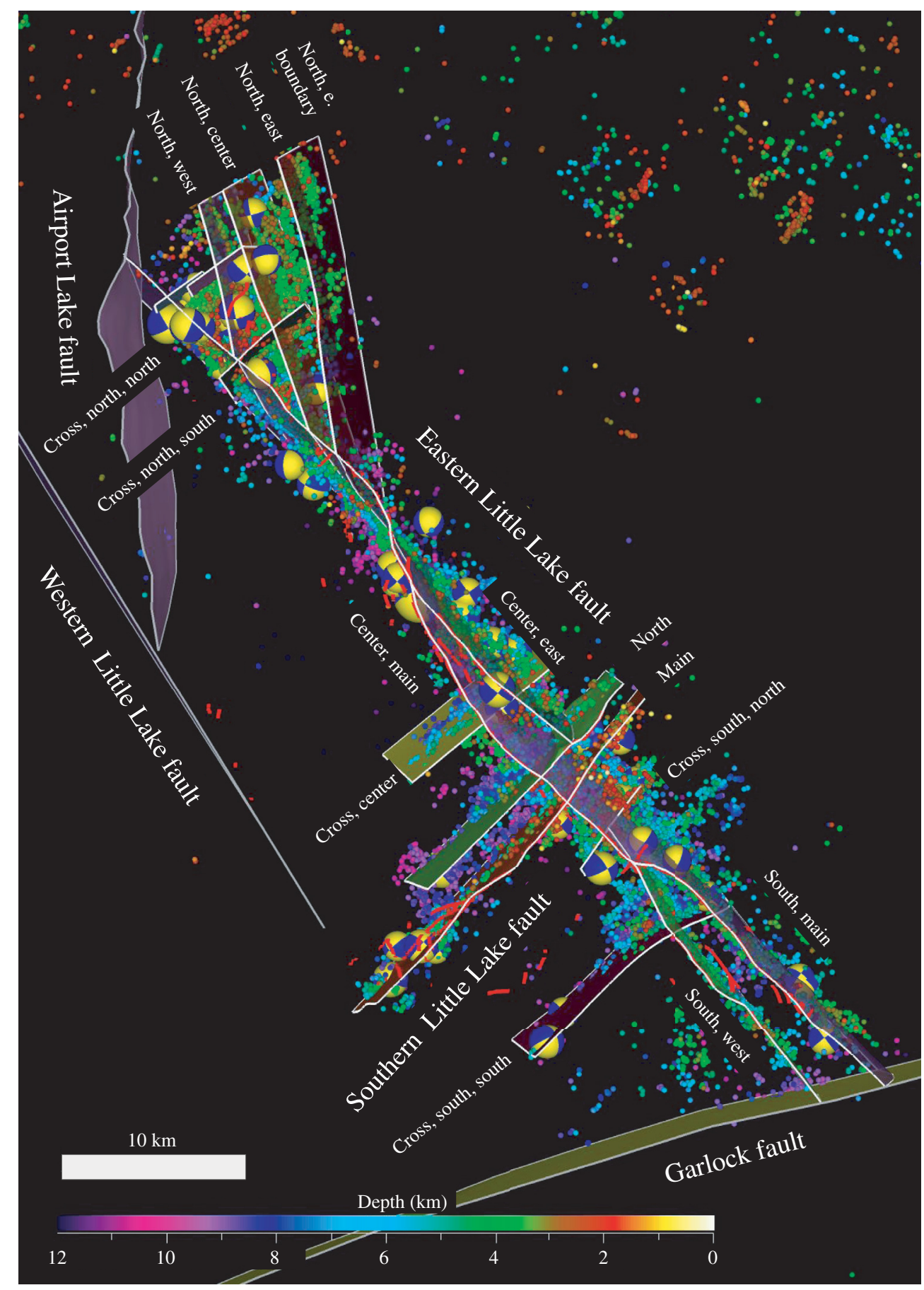

Figure 9. Map view of the final model of the 2019 Ridgecrest faults, including the ELLF and SLLF zones (colored surfaces).

elements. Our analysis defines that the northwest-southeasttrending elements are consistent with a series of long $(>8 \mathrm{~km})$ continuous fault segments. Specifically, our analysis of the hypocentral locations defines four fault segments that extend northward from the main trace of the ELLF (Fig. 7). These faults likely represent only the largest of a series of splays that define distributed deformation along the north extent of the rupture. The ELLF terminates to the north into the Airport Lake fault. However, the northern splay faults are limited by the northern extent of the seismicity and thus terminate to the south and east of the Airport Lake fault.

The most prominent feature of the Ridgecrest source model is the orthogonal, interlocking nature of the fault systems (Ross, Idini, et al., 2019; Hudnut et al., 2020). Our analysis shows that this result is supported by an objective, reproducible method of fault surface modeling based on the full complement of seismic and geologic map data that are available. The northwestsoutheast and northeastsouthwest faults in our model intersect at angles $85^{\circ}-90^{\circ}$ and generally interpenetrate one another (i.e., one fault system is not clearly displaced by the other). Various explanations have been offered for this pattern of orthogonal faulting, as a result of dynamic rupture processes (e.g., $\mathrm{Xu}$ and Ben-

across the SLLFs. About $18 \mathrm{~km}$ south of the $\mathbf{M} 7.1$ mainshock, the fault has a second, subparallel (western) splay illuminated by seismicity and ground surface ruptures. These two splays extend south for about $18 \mathrm{~km}$ and truncate into the Garlock fault. To the north of the mainshock, the seismicity becomes more broadly distributed, and small surface ruptures define both northwest-southeast- and northeast-southwest-trending
Zion, 2013) or reflecting distinct values of fault friction (Ross, Idini, et al., 2019; Hauksson et al., 2020). Moreover, such orthogonal patterns of faulting have been observed elsewhere in southern California and in other tectonic settings (e.g. Hudnut et al., 1987; Fukuyama, 2015). With the caveat that these patterns are generally rare, such cross faulting presents intriguing questions from a geologic and kinematic 
perspective. Specifically, large amounts of total displacement on faults should cause cross-fault structures to be displaced (offset). The lack of such resolvable offsets in Ridgecrest suggest that this sequence may not represent a characteristic rupture on this system, that is, that past and future events would generally not involve these same sets of faults and thus not result in the expected offsets of cross faults. Alternatively or in addition, this system may be viewed as immature, with only modest total (geological) fault offsets that cannot be resolved by the earthquake or fault trace datasets. In either case, the Ridgecrest event provides a clear description of the potential complexity of fault system ruptures. Indeed, expansion and improvements in fault trace maps and earthquake catalogs have led to the refinement of $3 \mathrm{~d}$ geometries for other strikeslip fault systems in the southern California CFM, including the definition of highly segmented systems with arrays of cross cutting fault splays (e.g., Plesch et al., 2016, 2019; Nicholson et al., 2019). The fault system illuminated by the Ridgecrest earthquake sequence unequivocally demonstrates that such complexities exists for some active strike-slip faults and thus highlight the importance of considering a wide range of multisegment rupture scenarios in regional hazard assessments. Our analysis seeks to represent the main elements of the Ridgecrest structure and to provide a set of fault surface representations to the community that can be used to support a wide range of earthquake science and hazard studies.

\section{CONCLUSIONS}

We applied an objective, reproducible method to define the 3D geometry of the faults that sourced the 2019 Ridgecrest earthquake sequence in California using hypocenters, focal mechanisms, and surface fault traces. These datasets are applied as weighted constraints, and include event catalogs enhanced by template matching (Ross, Trugman, et al., 2019; Hauksson et al., 2020), nodal planes from $\mathbf{M} \geq 4.0$ events, and groundverified surface rupture traces (Kendrick et al., 2019). The processes yielded a set of 14 major fault segments that are compatible with the representations of other regional faults in the SCEC CFM (Plesch et al., 2007, 2019; Nicholson et al., 2019). The 4 July 2019 (M 6.4) event ruptured the northeast-southwest trending SLLF that is illuminated by seismicity and has a nearly continuous mapped surface trace. A second, parallel fault identified by hypocenter distributions is located about $3 \mathrm{~km}$ to the northwest of the main SLLF. This splay has only limited mapped surface rupture and thus is largely blind. The 5 July 2019 (M 7.1) mainshock occurred on the ELLF, which trends northwest-southeast and includes numerous splays. There are two distinct splays in the epicentral zone, with the eastern splay sourcing the mainshock and several of the largest aftershocks occurring on the western splay. To the south, the ELLF consists of two parallel splays that terminate into the Garlock fault. To the north, the rupture is defined by a diffuse zone of seismicity, and the ELLF appears to terminate into the Airport Lake fault. This northern segment of the rupture includes a series of north-south-trending faults that terminate into the main trace of the ELLF, and northeastsouthwest-trending cross faults. We model the largest and most continuous of these faults.

In summary, our study of the Ridgecrest earthquake sequence defines several important characteristics of active strike-slip faults, including their (1) highly segmented nature, with splays that connect larger more continuous and planar segments; (2) subparallel, overlapping fault splays; (3) nonvertical fault dips in the shallow subsurface that steep to vertical surfaces at depth; and (4) fault segments that intersect (and in some cases interpenetrate) at high angles. Moreover, we demonstrate application of an objective and reproducible, constraint-based method to model these complex fault geometries using an array of datasets (template-matched and precisely located hypocenters, focal mechanisms, and field- and remotely sensed fault trace data) that can be applied to characterize earthquake sources in other tectonically active regions.

Our modeled fault surfaces for the 2019 Ridgecrest earthquake sequence are available as supplemental material to this article and through the SCEC CFM website (see Data and Resources). These fault representations are intended to facilitate a wide range of earthquake science and hazard studies.

\section{DATA AND RESOURCES}

Detailed rupture trace data (Kendrick et al., 2019; K. Scharer, personal comm., 2019) was obtained from https://response.scec.org (last accessed September 2019). We have used hypocenters from the California Institute of Technology (Caltech)/U.S. Geological Survey (USGS) Southern California Seismic Network (SCSN); doi: 10.7914/ SN/CI; stored at the Southern California Earthquake Data Center (doi: 10.7909/C3WD3xH1 and available at https://scedc.caltech.edu, last accessed September 2019). The hypocenters and magnitudes that are from the Caltech/USGS southern California earthquake catalog are described by Hutton et al. (2010). The most recent relocations of 2019 Ridgecrest seismicity and data availability are described in Hauksson et al. (2020). The quake template matching (QTM) catalog is available at https://scedc.caltech.edu/research-tools/QTM-ridgecrest.html (last accessed September 2019) and described in Ross, Trugman, et al. (2019). The digital fault representations prepared in this study are available in ASCII format in the supplemental material. They are provided in UTM zone 11 coordinates. In addition, these fault models will be incorporated in a subsequent release of the Southern California Earthquake Center (SCEC) Community Fault Model (CFM), available at https://www.scec.org/research/cfm (last accessed April 2020). Other utilized resources include the Quaternary fault and fold database for the United States by the USGS and California Geological Survey available at https://www.usgs.gov/natural-hazards/earthquake-hazards/faults (last accessed September 2019) and the SCEC CFM Viewer available at https://www.scec.org/research/cfm-viewer (last accessed April 2020).

\section{ACKNOWLEDGMENTS}

This research was partially funded by the Southern California Earthquake Center (SCEC) under Award Number 19102 and is SCEC 
Publication Number 10096. The SCEC is funded by National Science Foundation (NSF) Cooperative Agreement EAR-1600087 and the U.S. Geological Survey (USGS) Cooperative Agreement G17AC00047. The authors thank reviewers for their generous comments.

\section{REFERENCES}

Allen, C. R. (1957). San Andreas fault zone in San Gorgonio Pass, southern California, Geol. Soc. Am. Bull. 68, no. 3, 315-350.

Barnhart, W. D., G. P. Hayes, and R. D. Gold (2019). The July 2019 Ridgecrest, California, earthquake sequence: Kinematics of slip and stressing in cross-fault ruptures, Geophys. Res. Lett. 46, no. 21, 11,859-11,867, doi: 10.1029/2019GL084741.

Carena, S., and J. Suppe (2002). Three-dimensional imaging of active structures using earthquake aftershocks: The Northridge thrust, California, J. Struct. Geol. 24, 887-904, doi: 10.1016/S0191-8141 (01)00110-9.

Caumon, G., J. Renaudeau, M. Irakarama, P. Collon, L. Grose, G. Laurent, L. Ailleres, M. Varga, F. Wellmann, S. Lopez, et al. (2019). Implicit structural modeling of geological structures-A benchmark, RING Meeting Proceedings, Nancy, France, 10-13 September 2019.

Chen, K., J. Avouac, S. Aati, C. Millner, F. Zheng, and S. Chuang (2020). Cascading and pulse-like ruptures during the 2019 Ridgecrest earthquakes in the Eastern California Shear Zone, Nat. Comm. 11, 1-8, doi: 10.1038/s41467-019-13750-w.

Dibblee, T. (1973). Regional geologic map of San Andreas and related faults in Carrizo Plain, Temblor, Caliente, and La Panza Ranges and vicinity, California, USGS IMAP 757, doi: 10.3133/i757.

Evans, W. E., A. Plesch, J. H. Shaw, N. L. Pillai, E. Yu, M. Meier, and E. Hauksson (2020). A statistical method for associating earthquakes with their source faults in southern California, Bull. Seismol. Soc. Am. 110, 213-225, doi: 10.1785/0120190115.

Frank, T., A.-L. Tertois, and J.-L. Mallet (2007). 3D-reconstruction of complex geological interfaces from irregularly distributed and noisy point data, Comput. Geosci. 33, 932-943, doi: 10.1016/ j.cageo.2006.11.014.

Fukuyama, E. (2015). Dynamic faulting on a conjugate fault system detected by near-fault tilt measurements, Earth Planets Space 67, 38, doi: 10.1186/s40623-015-0207-1.

Harding, T. (1973). Newport-Inglewood trend, California-An example of wrenching style of deformation, AAPG Bulletin 57, 97-116.

Hauksson, E., and L. M. Jones (2020). Seismicity, stress state, and style of faulting of the Ridgecrest-Coso region from the 1930s to 2019: Seismotectonics of an evolving plate boundary segment, Bull. Seismol. Soc. Am. doi: 10.1785/0120200051.

Hauksson, E., K. Hutton, H. Kanamori, and L. Jones (1995). Preliminary report on the 1995 Ridgecrest earthquake sequence in Eastern California, Seismol. Res. Lett. 66, 54-60, doi: 10.1785/gssrl.66.6.54.

Hauksson, E., C. Yoon, E. Yu, J. R. Andrews, M. Alvarez, R. Bhadha, and V. Thomas (2020). Caltech/USGS Southern California Seismic Network (SCSN) and Southern California Earthquake Data Center (SCEDC): Data availability for the 2019 Ridgecrest sequence, Seismol. Res. Lett. doi: 10.1785/0220190290.

Huang, H., R. Bürgmann, L. Meng, K. Wang, and B. Rousset (2019). Spatio-temporal foreshock evolution of the 2019 M 6.4 and M 7.1 Ridgecrest, California earthquakes, Poster Presentation at the 2019 SCEC Annual Meeting, Palm Springs, California, 8-11 September 2019.

Hudnut, K. W., B. Brooks, K. Scharer, J. Hernandez, T. Dawson, M. Oskin, R. Arrowsmith, C. Goulet, K. Blake, M. Boggs, et al. (2020). Airborne lidar and electro-optical imagery along surface ruptures of the 2019 Ridgecrest earthquake sequence, Southern California, Seismol. Res. Lett. doi: 10.1785/0220190338.

Hudnut, K. W., L. Seeber, and J. Pacheco (1987). Cross-fault triggering in the November 1987 Superstition Hills earthquake sequence, southern California, Geophys. Res. Lett. 16, 199-202, doi: 10.1029/GL016i002p00199.

Hutton, K., J. Woessner, and E. Hauksson (2010). Earthquake monitoring in Southern California for seventy-seven years (1932-2008), Bull. Seismol. Soc. Am. 100, 423-446, doi: 10.1785/0120090130.

Jennings, C. W., and W. A. Bryant (2010). Fault activity map of California, California Geological Survey Geologic Data Map No. 6, Map Scale 1:750,000.

Kendrick, K. J., S. O. Akciz, S. J. Angster, J. Avouac, J. L. Bachhuber, S. E. Bennett, K. Blake, S. Bork, B. A. Brooks, P. Burgess, et al. (2019). Geologic observations of surface fault rupture associated with the Ridgecrest M 6.4 and M 7.1 earthquake sequence by the Ridgecrest Rupture Mapping Group, Poster Presentation at the 2019 SCEC Annual Meeting, Palm Springs, California, 8-11 September 2019.

Kozaci, O., C. M. Madugo, J. L. Bachhuber, C. Hitchcock, A. R. Kottke, and K. Herr (2019). Rapid post-earthquake reconnaissance and paleoseismic trenching preliminary results for the M 6.4 and M 7.1 Ridgecrest earthquake sequence, Southern California, Poster Presentation at the 2019 SCEC Annual Meeting, Palm Springs, California, 8-11 September 2019.

Lawson, A. C., A. O. Leuschner, G. K. Gilbert, G. Davidson, H. F. Reid, C. Burkhalter, J. C. Branner, and W. W. Cambell (1908). The California earthquake of April 18, 1906, Report of the State Earthquake Investigation Commission, California State Earthquake Investigation Commission.

Liu, C., T. Lay, E. Brodsky, D. C. Kelian, and X. Xiong (2019). Coseismic rupture process of the large 2019 Ridgecrest earthquakes from joint inversion of geodetic and seismological observations, Geophys. Res. Lett. 46, no. 21, 11,820-11,829, doi: 10.1029/ 2019GL084949.

Magistrale, H., S. Day, R. Clayton, and R. Graves (2000). The SCEC Southern California reference three-dimensional seismic velocity model version 2, Bull. Seismol. Soc. Am. 90, S65-S76, doi: $10.1785 / 0120000510$.

Mallet, J.-L. (1992). Discrete smooth interpolation in geometric modeling, Comput. Aided Des. 24, no. 4, 178-191.

Muron, P., A.-L. Tertois, J.-L. Mallet, and J. Hovadik (2005). An efficient and extensible interpolation framework based on the matrix formulation of the discrete smooth interpolation, 25th Gocad Meeting Proceedings, Nancy, France, 6-9 June 2005.

Nazareth, J. J., and E. Hauksson (2004). The seismogenic thickness of the Southern California crust, Bull. Seismol. Soc. Am. 94, no. 3, 940-960, doi: 10.1785/0120020129.

Nicholson, C., A. Plesch, C. C. Sorlien, J. H. Shaw, S. T. Marshall, and E. Hauksson (2019). Continued updates, expansion and improvements to the Community Fault Model (CFM version 5.3), Poster Presentation at the 2019 SCEC Annual Meeting, Palm Springs, California, 8-11 September 2019. 
Plesch, A., and O. Oncken (1999). Orogenic wedge growth during collision-Constraints on mechanics of a fossil wedge from its kinematic record (Rhenohercynian FTB, Central Europe), Tectonophysics 309, 117-139.

Plesch, A., C. Nicholson, C. C. Sorlien, J. H. Shaw, and E. Hauksson (2016). CFM version 5.1: New and revised 3D fault representations and an improved database, Poster Presentation at the 2016 SCEC Annual Meeting, Palm Springs, California, 11-14 September 2016.

Plesch, A., J. H. Shaw, C. Benson, W. A. Bryant, S. Carena, M. Cooke, J. F. Dolan, G. Fuis, E. Gath, L. Grant, et al. (2007). Community Fault Model (CFM) for Southern California, Bull. Seismol. Soc. Am. 97, no. 6, 1793-1802.

Plesch, A., J. H. Shaw, Z. E. Ross, and E. Hauksson (2019). Detailed 3D source fault representations for the 2019 Ridgecrest earthquake sequence, Poster Presentation at the 2019 SCEC Annual Meeting, Palm Springs, California, 8-11 September 2019.

Ponti, D. J., J. Blair, C. M. Rosa, K. Thomas, A. J. Pickering, S. Akciz, S. Angster, J.-P. Avouac, J. Bachhuber, S. Bacon, et al. (2020). Documentation of surface fault rupture and ground deformation features produced by the Ridgecrest M 6.4 and M 7.1 earthquake sequence of 4 and 5 July 2019, Seismol. Res. Lett. doi: 10.1785/0220190322.

Riesner, M., P. Durand-Riard, J. Hubbard, A. Plesch, and J. H. Shaw (2017). Building objective 3D fault representations in active tectonic settings, Seismol. Res. Lett. 88, 831-839, doi: 10.1785/ 0220160192.

Roquemore, G. R., and J. T. Zellmer (1986). Neotectonic development of the Coso Range, California, Geol. Soc. Am. Abstr. Progr. 18, no. $2,178$.

Ross, Z. E., B. Idini, Z. Jia, O. L. Stephenson, M. Zhong, X. Wang, Z. Zhan, M. Simons, E. J. Fielding, S. H. Yun, et al. (2019). Hierarchical interlocked orthogonal faulting in the 2019 Ridgecrest earthquake sequence, Science 366, no. 6463, 346-351.

Ross, Z. E., D. T. Trugman, E. Hauksson, and P. M. Shearer (2019). Searching for hidden earthquakes in Southern California, Science 364, no. 6442, 767-771.

Seeber, L., and J. G. Armbruster (1995). The San Andreas Fault system through the Transverse Ranges as illuminated by earthquakes, $J$. Geophys. Res. 100, no. B5, 8285-8310, doi: 10.1029/94JB02939.
Shaw, J. H., A. Plesch, J. F. Dolan, T. L. Pratt, and P. Fiore (2002). Puente Hills blind-thrust system, Los Angeles, California, Bull. Seismol. Soc. Am. 92, 2946-2960.

Shaw, J. H., A. Plesch, C. Tape, M. P. Suess, T. H. Jordan, G. Ely, E. Hauksson, J. Tromp, T. Tanimoto, R. Graves, et al. (2015). Unified structural representation of the southern California crust and upper mantle, Earth Planet. Sci. Lett. 415, 1-15.

Stewart, J. P., S. J. Brandenberg, P. Wang, C. N. Chukwuebuka, K. Hudson, S. Mazzoni, Y. Bozorgnia, K. W. Hudnut, C. A. Davis, S. K. Ahdi, et al. (2019). Preliminary report on engineering and geological effects of the July 2019 Ridgecrest earthquake sequence, Geotechnical Extreme Event Reconnaissance Association Report GEER-064 (v.2), doi: 10.18118/G6H66K.

Su, M., P. J. Maechling, S. T. Marshall, C. Nicholson, A. Plesch, J. H. Shaw, E. Pauk, T. T. Huynh, and E. H. Hearn (2019). A queryable map-based web interface to the SCEC Community Fault Model, Poster Presentation at the 2019 SCEC Annual Meeting, Palm Springs, California, 8-11 September 2019.

Süss, M. P., and J. H. Shaw (2003). P-wave seismic velocity structure derived from sonic logs and industry reflection data in the Los Angeles basin, California, J. Geophys. Res. 108, no. B3, doi: 10.1029/2001JB001628.

Sylvester, A. (1988). Strike-slip faults, Geol. Soc. Am. Bull. 100, 1666-1703. Thompson Jobe, B., B. Philibosian, C. Chupik, D. Timothy, S. E. K. Bennett, R. Gold, C. B. DuRoss, T. Ladinsky, K. J. Kendrick, and E. K. Haddon (2020). Evidence of previous faulting along the 2019 Ridgecrest earthquake ruptures, Bull. Seismol. Soc. Am. doi: 10.1785/0120200041.

Wills, C. J. (1988). Little Lake and Airport Lake fault zones, California, California Division of Mines and Geology Fault Evaluation Report FER-199, 11 pp.

$\mathrm{Xu}, \mathrm{S}$., and Y. Ben-Zion (2013). Numerical and theoretical analyses of in-plane dynamic rupture on a frictional interface and off-fault yielding patterns at different scales, Geophys. J. Int. 193, 304-320, doi: $10.1093 /$ gji/ggs105. 